\title{
Perceived structure and the maintenance of attention
}

\author{
ELIZABETH PUGZLES LORCH \\ University of Kentucky, Lexington, Kentucky
}

(Robert F. Lorch, Jr., Sponsor)

\begin{abstract}
It was hypothesized that people can attain complex, hierarchically organized structures for incoming task-relevant information; that the boundaries between the units of information highest in the hierarchy constitute major breaks in the processing and integration of information; and that these major "breakpoints" are times when people are especially vulnerable to distraction. Subjects were trained to perceive formally defined structures in sequences of stimuli. After training, subjects performed a continuous prediction/classification task, using the same sequences of stimuli. Distractors were present during some stimulus events, occurring at each level of the unit hierarchy. Subjects' response times increased as unit level increased and in the presence of distraction. However, the major hypothesis was not confirmed: The effect of distraction did not vary with unit level. An alternative to this hypothesis is discussed, as well as limitations of the present test.
\end{abstract}

Much of human behavior is goal directed, and much of the information necessary to meet goals becomes available sequentially. In order to effectively use sequentially presented information, a person must organize and integrate successive pieces of information as they relate to goals. If a task is complex, an individual may have to build a hierarchical structure of task-relevant information, in which discrete pieces of information are integrated into higher order components. Such a structure could reduce the individual's memory load for past events and help to build anticipations of future higher order components (e.g., Royer, 1967).

The notion that people develop structures that affect their behavior and the way they obtain information from the world is hardly unknown. It is the core of several theoretical syntheses of physiological psychology and skilled behavior (e.g., Bindra, 1978; Hebb, 1949); is central to theoretical views of the representation of texts and plans (e.g., Graesser, 1978; Kintsch \& van Dijk, 1978; R. F. Lorch, E. P. Lorch, \& Matthews, 1985; Mandler, 1978; Vipond, 1980); has been supported in studies of the perception of ongoing behavior, events, and sequences (e.g., Neisser \& Becklen, 1975; Newtson, 1976; Pick, 1979); and has contributed to explanations of the learning of sequential patterns of simple stimuli (Royer, 1967; Restle, 1970; Restle \& Brown, 1970).

A summary of these diverse bodies of research indicates that people construct structures from lower to higher level units of information, and use high level units to integrate information and direct further information pickup.

I am grateful for the generous help of Daniel Anderson, Rex Bradford, Robert Lorch, Rick Robson, Arnold Well, Nancy Myers, and Grace Craig. Requests for reprints should be sent to Elizabeth Pugzles Lorch, Department of Psychology, University of Kentucky, Lexington, KY 40506.
Royer (1967), for example, commented, "A point in the sequence where a transition from one unit to another occurs constitutes a juncture or point of articulation around which to organize the sequence into a pattern'" (p. 201). The points between high level units, in particular, are seen as times to retrieve or monitor the ongoing organization and to judge how far ahead information and/or likely responses can be anticipated (Graesser, 1978; Kahneman, 1973; R. F. Lorch et al., 1985; Schank \& Abelson, 1977; Vipond, 1980).

Following from such interpretations, the principal hypothesis tested in the present experiment is that attention to an ongoing task is most vulnerable to distraction at points between the highest level units perceived in the structure. If major breaks between units represent breaks or changes in processing as well, individuals may be more open to irrelevant, as well as task-relevant, information at these times. In contrast, low level unit boundaries or points within units are likely to be integrated within higher order structural components, making distraction less likely. Although this hypothesis has not been directly tested, indirect support comes from studies indicating that stimuli or sequences perceived as coherent units are likely to resist interruption from other events (Broadbent, 1977; Fodor \& Bever, 1965; Kahneman, 1973; Neisser \& Becklen, 1975; Neisser \& Dube, 1978).

The subjects were trained to perceive patterns in two sequences of stimulus information. The patterns were defined by formal structures that specified hierarchies of units of information. After training, the subjects performed a continuous prediction task in the context of an outer space video game. Sequences of stimuli appearing in the prediction task were in accord with those learned in training. Between sequences, an event informed the subjects of the next sequence. The boundaries between 
this event and the two sequences surrounding it were presumed to be the highest level breaks in the structure. The subjects were instructed to predict the next stimulus as quickly as possible each time a specified response signal occurred on the screen. If they did not know the identity of the next stimulus, they could respond after it had actually appeared. During some trials, one of several types of distraction occurred simultaneously with the response signal, but in another location. The occurrence of distractors was distributed across unit levels. The subjects' response times (RTs) and errors were recorded.

\section{METHOD}

\section{Subjects}

The subjects were 57 undergraduate students who received credit for participation. Some of the data of 13 subjects were lost, due to computer malfunction (4 subjects) or difficulty with the procedure (9 subjects).

\section{Stimuli}

Stimulus presentation was controlled by a Cromemco Z-2D microcomputer system equipped with a color videographics generator $(64 \times$ 64 graphics grid) and connected to a 17 -in. color monitor.

The background color for all stimuli and all periods between stimulus presentations was off-white. All stimulus items described below appeared in either the upper or lower half of the screen.

Five distinct but similarly sized forms were identified for the subjects. The average height of the forms was $5.21 \mathrm{~cm}$ and the average width was $9.81 \mathrm{~cm}$. One form, which resembled a bull's-eye, was the response signal. The other four resembled schematic spaceships, and were designated Squadron Leader 1, Squadron Leader 2, Spaceship 1, and Spaceship 2. Each differed from the others in overall shape and color composition.

There were three types of distractors, which always appeared in the opposite half of the screen from the response signal, squadron leader, or spaceship. The space scene distractor was a schematic outer space display that filled half of the screen. Its background was midnight blue; it contained a yellow crescent moon, a green planet around which a small red satellite appeared to circle, and $\mathbf{4 0}$ white stars that appeared to twinkle.

Verbal distractors were selected from a list of 128 words, colloquial expressions, and phrases. They ranged from four to six characters in length; each character's maximum height and width were $2.84 \mathrm{~cm}$ and $2.67 \mathrm{~cm}$, respectively. The color of each presentation of a verbal distractor was randomly selected from all colors distinct from the background. Because distractors were said to be "enemy interference," they included messages such as "uh-oh!", "dummy", and "tired?"

The flying ball distractor resembled the tennis or Ping-Pong "balls" common in video games; the direction and speed of its apparent movement were controlled by random selections of directions and velocities on the $x$ - and $y$-axes. The color of the $0.41 \mathrm{~cm} \times 0.53 \mathrm{~cm}$ ball was randomly selected from colors distinct from the background. The variation in velocities caused the ball to appear at times to drift and at times to zoom across the screen.

\section{Design}

Each subject experienced 30 instances of each of two possible stimulus sequences, divided into 10 blocks separated by rest periods. Each of the 6 instances within a block was randomly selected from the two sequences, with a limit of 30 of each sequence over the entire experiment. Each presentation of a stimulus in a sequence constituted a trial.

The sequences were generated from a modification of Restle's (1970; Restle \& Brown, 1970) system for representing sequential stimuli. Two operations in this system are repetition $[\mathbf{R}(x)=$ start sequence with $x$ and repeat $x]$ and transposition [T $(x)=$ start sequence with $x$ and add $x+1]$. The operations can be nested $[\operatorname{R}(T(x))=x, x+1, x, x+1]$, or repeated, using subscripts $\left.\left[\mathrm{R}_{(\mathrm{T}}(x)\right)=x, x+1, x+2, x, x+1, x+2\right]$.
In the present application, numbers generated signify the number of repetitions of a particular spaceship before a change to the other spaceship (given an arbitrary starting point).

Sequence 1 was defined as $T_{2}(R(R(1)))=111122223333$. Beginning with Spaceship 1, that structure translated into the following sequence of spaceships: 121211221122111222111222. Sequence 2 was defined as $-T_{3}(R(4))=44332211$. Beginning with Spaceship 2, that structure represented the following sequence of spaceships: 22221111222111221121 .

Sequence 1 was always immediately preceded by the presentation of Squadron Leader 1 , and Sequence 2 was preceded by Squadron Leader 2. Thus, the appearance of a particular squadron leader informed the subject of the next sequence.

Unit levels, corresponding to the level of the unit boundary that a given event followed, were assigned to each event in each sequence. For example, in Sequence 1, Level $w$ (within) units corresponded to repetitions of spaceships, Level 1 units followed boundaries between components on the innermost repetition, Level 2 followed boundaries between components on the second level of repetition, and Level 3 followed boundaries between transpositions. Assignment was similar for Sequence 2, except that there were no Level 3 units. In both sequences, the squadron leader and the first spaceship were designated Level $e$ and $b$ units, respectively, because they followed boundaries that involved major breaks in structure. Each Level $e$ unit (squadron leader) followed the end of a sequence; each Level $b$ unit signified the beginning of a sequence, as specified by the squadron leader.

Distractors were presented on $20 \%$ of all trials. The type of distractor (space scene, verbal, or flying ball) was randomly selected for each trial. For Sequence 1, distractors occurred on 24 of $60 \mathrm{Level} b$ and $e$ units, 24 of 60 Level 3 units, 30 of 90 Level 2 units, 30 of 180 Level 1 units, and 42 of 360 Level $w$ units. For Sequence 2, distractors occurred on 26 of 60 Level $b$ and $e$ units, 33 of 90 Level 2 units, 32 of 120 Level 1 units, and 36 of 360 Level $w$ units.

\section{Procedure}

Each subject was seated approximately $1 \mathrm{~m}$ from the screen and given written instructions for playing the video game, in which the task was to provide information to the subject's starbase. Whenever the response signal appeared, the subject was to press one of three buttons, signifying Spaceship 1, Spaceship 2, or squadron leader. Instructions emphasized both speed and accuracy, and informed the subject of the possibility of distractors ("enemy interference").

The subject received demonstrations of the stimuli, practice with the procedure, and training in the two sequences. Training continued until the subject consistently identified all stimuli and the responses associated with them, and could predict the sequences without error (not necessarily with facility). The experimenter then initiated the first game (block).

Each trial within a sequence began with presentation of the response signal for $500 \mathrm{msec}$, in either the upper or lower half of the screen. Location was randomly determined. The stimulus (spaceship or squadron leader) for that trial replaced the response signal on the screen and remained on for $100 \mathrm{msec}$ after the subject responded correctly. If a correct response preceded the stimulus, the stimulus was displayed for $100 \mathrm{msec}$. If a distractor was shown, its onset coincided with that of the response signal and its offset coincided with that of the stimulus. Intertrial interval was varied randomly between 100 and $1,100 \mathrm{msec}$. After all trials of six sequences were completed, the subject's score for the block (based on speed and accuracy) was displayed. Short rest periods were provided between blocks. The subjects' RTs were accurate to $10 \mathrm{msec}$.

\section{RESULTS}

\section{Reaction Times}

Sequences 1 and 2 were analyzed separately as replications of the experimental design. Only analyses of RTs on errorless trials are reported; the data including all trials are more variable but reveal the same pattern of results. 
Repeated measures ANOVAs were conducted on mean RTs, with independent variables of unit level (5 or 6), presence of distraction (2), and trial block (5). For the analyses, a block was defined as six instances of the sequence. The 13 subjects whose data were incomplete were eliminated from these analyses. Planned comparisons followed the Bonferroni procedure. All reported tests are reliable at or beyond the .05 level.

Mean RTs for each sequence as a function of unit level and distraction are presented in Table 1 . RTs varied significantly across unit levels [Sequence 1: $F(5,215)=$ 31.30; Sequence 2: $F(4,172)=33.53$ ]. Pairwise comparisons between adjacent members of the unit hierarchies revealed that for Sequence 1, RTs on Level $e$ trials were greater than those on Level $b$ trials $[F(1,43)=14.51]$, which were greater than those on Level 3 trials $[F(1,43)$ $=44.73$ ]. RTs on Level 1,2 , and 3 trials were not significantly different from one another, but all were significantly greater than RTs on Level $w$ trials $[F(1,43)=$ 8.78]. For Sequence 2, RTs at each unit level were significantly greater than those at the next lower level in the hierarchy $[F(1,43)=14.51,13.32,47.91,5.44$, and 6.10 in descending order].

RTs were significantly greater when distraction was present than when it was absent, for both Sequence 1 and Sequence $2[F(1,43)=8.40$ and 7.05 , respectively $]$. As seen in Table 1, however, the effect of distraction did not vary systematically over the unit levels of either sequence [Sequence 1: $F(5,215)=0.08$; Sequence $2 F(4,172)=$ $1.52]$, and actually reversed sign at the highest unit level of Sequence 2.

The subjects' RTs decreased with practice for both Sequence 1 and Sequence $2[F(4,172)=87.89$ and 58.48, respectively]. There was also a blocks $\times$ unit interaction for Sequence $1[F(20,860)=6.29]$ and for Sequence 2 $[F(16,688)=6.91]$. The difference in RTs between the unit levels was greater at the outset of the session than at its end, due to larger practice effects for the higherlevel units [Sequence 1: $F(5,215)=10.43$; Sequence 2: $F(4,172)=12.02$, for the units $\times$ blocks linear component].

The data from all subjects were used and contributions of additional independent variables (distraction on the previous trial, error on the previous trial, intertrial inter-

Table 1

Mean Reaction Times (in Milliseconds) as a Function of Unit Level and Distraction for Sequence 1 and Sequence 2

\begin{tabular}{lrrrrrrr}
\hline & \multicolumn{7}{c}{ Unit Level } \\
\cline { 2 - 8 } & $e$ & $b$ & 3 & 2 & 1 & $w$ & Marginal \\
\hline Distraction & 1,108 & 714 & 500 & 488 & 493 & 470 & 629 \\
No Distraction & 1,043 & 649 & 456 & 447 & 448 & 413 & 576 \\
Difference & 65 & 65 & 44 & 41 & 45 & 57 & \\
& \multicolumn{7}{c}{ Sequence 2} \\
Distraction & 1,019 & 714 & 486 & 481 & 429 & 626 \\
No Distraction & 1,046 & 658 & 450 & 414 & 386 & 591 \\
Difference & -27 & 56 & 36 & 67 & 43 & \\
\hline
\end{tabular}

val) were examined in regression analyses that predicted RT on each errorless trial separately for Sequences 1 and 2. The subject's average RT was entered first, so that between-subjects variance could be extracted from the total variance in RT. Each within-subjects main effect was tested by evaluating its further contribution to the regression equation. Interactions of interest were tested by creating a new variable (or variables) that was the product of the interaction's main-effect components, then entering the variable after average RT and the component main effects.

The results of these analyses will not be reported in detail, because they reveal essentially the same effects as did the ANOVAs (i.e., RT decreased with practice, increased with distraction, and varied over unit levels). In addition, distraction or an error on the previous trial slowed RT on the predicted trial, and RTs decreased as intertrial interval increased. Most important, despite the tremendous power of the analyses $(40,023$ and 34,036 cases for Sequences 1 and 2, respectively), there were no systematic relations between unit structure and distraction on either the predicted or previous trial.

\section{Error Rates}

The mean error rate over all trials was 0.06 for both sequences. Repeated measures ANOVAs on error rates produced results similar to those of the RT analyses. The same patterns of differences across unit levels were found $[F(5,215)=21.57$ for Sequence 1 and $F(4,172)=17.90$ for Sequence 2]; however, there were no effects of distraction. Error rates decreased across blocks $[F(4,172)$ $=26.35$ and 35.65 for Sequences 1 and 2 , respectively], with practice effects greater for high-level units than for low-level units $[F(5,215)=7.16$ for Sequence 1 and $F(4,172)=10.58$ for Sequence 2$]$.

\section{DISCUSSION}

The results provide evidence of the influence of structures perceived in stimulus sequences on performance of a classification/prediction task. On trials following boundaries between units higher in the hierarchical structure, subjects' responses were slower and less accurate. The structures as defined, then, are psychologically real for the subject: The higher the level of the boundary, the more information the subject must integrate to produce the response and perhaps prepare for future responses. The subjects apparently improved their ability to make the more complex integrations, because RTs and error rates decreased more steeply for higher level units.

The findings also indicate that the distractors effectively impeded performance. The subjects' responses were slower when distraction was present, and the effect remained relatively constant throughout the experiment. Despite the power of the regression analyses to detect very small effects, however, there was no evidence to support the major hypothesis that vulnerability to distraction depends on unit level within a structure.

A straightforward interpretation of these results is that irrelevant stimuli have only momentary effects on processing of a relevant stimulus. For example, several investigators have proposed that an irrelevant stimulus may elicit an orienting response, delaying a relevant response until the individual has the opportunity to habituate to the irrelevant stimulus (E. P. Lorch, Anderson, \& Well, 1984; Reisberg, Baron, \& Kemler, 1980; Waters, McDonald, \& Koresko, 1977). Interference would be a function of the potency of the irrelevant stimulus to elicit an orienting 
response, but might be unrelated to the organization of the relevant task. In the present experiment, the variety and unpredictability of distractors would be expected to prevent habituation, resulting in the relatively constant interference observed across this experiment.

It is also possible that the major hypothesis is valid, although it was not supported in the context of the present task. It may apply in situations where the flow of information is more meaningful, such as in building complex physical structures, in processing text, or in comprehending televised material. A complete test of the hypothesis requires examination of a wider range of situations than the single instance explored in the present investigation.

\section{REFERENCES}

BinDRA, D. (1978). How adaptive behavior is produced: A perceptualmotivational alternative to response-reinforcement. The Behavioral \& Brain Sciences, 1, 41-91.

BroadBENT, D.E. (1977). The hidden preattentive processes. The American Psychologist, 32, 109-118.

FODOR, J. A., \& BEVER, T. G. (1965). The psychological reality of linguistic segments. Journal of Verbal Learning \& Verbal Behavior, 4, 414-420.

Graesser, A. C. (1978). How to catch a fish: The memory and representation of common procedures. Discourse Processes, 1, 72-89.

HeBB, D. O. (1949). Organization and behavior. New York: Wiley.

Kahneman, D. (1973). Attention and effort. Englewood Cliffs, NJ: Prentice-Hall.

KINTSCH, W., \& VAN DiJK, T. A. (1978). Toward a model of discourse comprehension and production. Psychological Review, 85, 363-394.

LorCh, E. P., ANDERson, D. R., \& Well, A. D. (1984). Effects of irrelevant information on speeded classification tasks: Interference is reduced by habituation. Journal of Experimental Psychology: Human Perception \& Performance, 10, 850-864.

LoRCh, R. F., JR., LorCh, E. P., \& MaTthews, P. D. (1985). Online processing of the topic structure of a text. Journal of Memory \& Language, 24, 350-362.
Mandler, J. M. (1978). A code in the node: The use of a story schema in retrieval. Discourse Processes, 1, 14-35.

NeIsSER, U., \& BeCKLEN, R. (1975). Selective looking: Attending to visually specified events. Cognitive Psychology, 7, 480-494.

NeISSER, U., \& DUBE, E. F. (1978, April). Interrupting the perceptual cycle: When do we notice unexpected events? Paper presented at the annual meeting of the Eastern Psychological Associaton, Washington, DC.

NeWTSON, D. (1976). The perceptual organization of ongoing behavior. Journal of Experimental Social Psychology, 12, 436-450.

PICK, A. D. (1979). Listening to melodies: Perceiving events. In A. D. Pick (Ed.), Perception and its development: A tribute to Eleanor J. Gibson. Hillsdale, NJ: Erlbaum.

Reisberg, D., BARON, J., \& Kemler, D. G. (1980). Overcoming Stroop interference: The effects of practice on distractor potency. Journal of Experimental Psychology: Human Perception \& Performance, 6, $140-150$.

Restle, F. (1970). Theory of serial pattern learning: Structural trees. Psychological Review, 77, 481-495.

Restle, F., \& Brown, E. (1970). Organization of serial pattern learning. In G. H. Bower \& J. T. Spence (Eds.), The psychology of learning and motivation: Advances in research and theory (Vol. 4). New York: Academic Press.

ROYER, F. L. (1967). Sequential complexity and motor response rates. Journal of Experimental Psychology, 74, 199-202.

SCHANK, R., \& AbELSON, R. (1977). Scripts, plans, goals, and understanding. Hillsdale, NJ: Erlbaum.

VIPOND, D. (1980). Micro- and macroprocesses in text comprehension. Journal of Verbal Learning \& Verbal Behavior, 19, 276-296.

WATERS, W. F., MCDONALD, D. G., \& KoRESKo, R. L. (1977). Habituation of the orienting response: A gating mechanism subserving selective attention. Psychophysiology, 14, 228-236.

(Manuscript received for publication September 12, 1986.) 